\title{
As concepções sobre Ser Vivo/Célula dos Estudantes do 3 semestre do Curso de Engenharia de Pesca do Campus XXIV- Xique-Xique-BA
}

\section{RESUMO}

Darcy Ribeiro de Castro

dcastro@uneb.br

Universidade do Estado da Bahia, XiqueXique, Bahia, Brasil

Jacqueline de Araújo Guerra jacquelineguerra02@hotmail.com Estado da Bahia, XiqueXique, Bahia, Brasil

Keisyara Bonfim dos Santos Keisyara santos@hotmail.com 000-0003-3661-0698

Universidade do Estado da Bahia, XiqueXique, Bahia, Brasil

Nadijara Pereira dos Santos nadjara pereira@hotmail.com

0000-0002-6560-146X

Universidade do Estado da Bahia, XiqueXique, Bahia, Brasil

Samara Rocha Mendes dos

\section{Santos}

samara rocha2015@hotmail.com

0000-0003-1937-6959

Estado da Bahia, Xique-

Xique, Bahia, Brasil

Taliany Santos de Amorim talianysantosdeamorim@yahoo.com.br 0000-0003-1937-6959

Universidade do Estado da Bahia, XiqueXique, Bahia, Brasil
Este trabalho trata da formação de conceitos científicos no Ensino Superior do Curso de Engenharia de Pesca da Universidade do Estado da Bahia (UNEB), Campus XXIV- XiqueXique-BA mediante conhecimentos adquiridos pelos alunos em disciplinas afins com as ciências biológicas. Envolveu 8 estudantes do 3으 semestre do ciclo básico. Teve como base as concepções espontâneas e científicas de estudantes sobre ser vivo/célula apoiada nas fases do desenvolvimento estudadas por Vygotsky (pensamento abstrato). Objetivamos analisar os conhecimentos dos alunos sobre célula, diferenciação celular, crescimento, respiração, reprodução, nutrição, herança e unidade. Utilizamos a pesquisa qualitativa vinculada a entrevista semiestruturada. Os dados foram analisados, segundo a orientação do método dialético, sendo as respostas dos alunos agrupadas em categorias conceituais, comparadas e discutidas de acordo com os referenciais apresentados. Evidenciamos os mecanismos envolvidos na assimilação dos conceitos espontâneos o e científicos pelos alunos, destacando suas potencialidades e dificuldades de compreensão.

PALAVRAS-CHAVE: Ser vivo. Célula. Conceito científico. 


\section{INTRODUÇÃO}

Este trabalho trata da formação de conceitos científicos no Ensino Superior, a partir dos conhecimentos prévios dos alunos, com base nas fases do desenvolvimento estudadas por Vygotsky $(1991,2010)$. Consideramos para tal, a fase de pensamento abstrato que persiste no ser humano após a adolescência, na sua relação com o pensamento por complexo. Entendemos que o pensamento conceitual poderá não ter sido bem definido na escolaridade anterior à graduação por conta das dificuldades inerentes ao ensino-aprendizagem no Ensino Fundamental e Médio: falta de professores habilitados na área, de reconhecimento escolar da importância do trabalho prático e instalações físicas laboratoriais, dentre outras.

O presente estudo, apoiado na perspectiva construtivista Histórico-Cultural de Vygotsky sobre a construção dos conceitos científicos, pode possibilitar a formulação de uma melhor compreensão sobre as formas de concepção dos alunos (as) com respeito aos conteúdos de estrutura e funcionalidade de ser vivo/célula e a descrição que eles fazem para compreendê-los. A Teoria HistóricoCultural consta de conceitos fundamentais para a realização deste trabalho, tais como desenvolvimento humano, conhecimento espontâneo/cientifico e zona de desenvolvimento. Essa abordagem poderá ser usada como referência para se analisar o conhecimento biológico dos alunos do ciclo básico do curso de Engenharia de Pesca (até 3 o semestre), Universidade do Estado da Bahia-UNEB, Campus XXIV.

Para isto é fundamental se investigar o que os estudantes do curso de engenharia de pesca (ciclo básico) sabem sobre a estrutura e funcionalidade de seres vivos, tendo em vista os problemas na escolaridade anterior mencionados anteriormente e que podem se perpetuar na graduação. Acreditamos que o referido impasse ocorre na universidade devido à falta do ensino em disciplinas específicas como biologia geral e biologia celular/molecular. Tivemos como ponto de partida para tal investigação, os seguintes questionamentos: é possível descrever os conceitos envolvidos na compreensão dos conteúdos de ser vivo/célula pelos estudantes de Engenharia de Pesca (ciclo básico) após as aulas ministradas pelos professores (as) em disciplinas afins? Até que ponto os estudantes passaram a conhecer os conteúdos biológicos nessa área ou quais são os conceitos assimilados? Em que esse conhecimento poderá contribuir para a universidade, no sentido de possibilitar avanços conceituais dos alunos nas disciplinas correlatas ao longo do curso, com vistas a contribuir para uma melhor formação profissional?

Para buscar responder a estas perguntas, buscamos identificar e analisar os conhecimentos dos alunos sobre os conceitos de seres vivos (célula, diferenciação celular, crescimento, respiração, reprodução, alimento/nutriente, herança, unidade e hábito de vida). A partir disto, procuramos conhecer melhor as dificuldades e as potencialidades de compreensão dos alunos (pontos fracos e fortes) em relação à estrutura e funcionalidade de ser vivo/célula, com vistas a contribuir com a formação deles na sequência do curso, com base no trabalho relacionado com as disciplinas correlatas. 


\section{2- REVISANDO CONCEITOS NA ÁREA}

A trajetória de formação de conceitos envolve três fases básicas: agregação desorganizada, pensamento por complexo e conceitos verdadeiros. Destacamos neste trabalho a relação entre a segunda fase (complexo) e a formação de conceitos verdadeiros (VYGOTSKY, 1991; 2010).

A fase da formação de conceitos que envolvem muitas variações de pensamento é chamada de pensamento por complexos. Um complexo é caracterizado por ligações concretas e factuais entre seus componentes, e não abstratas e lógicas, como no pensamento conceitual. A criança e o adolescente caminham em direção ao pensamento objetivo, pois as ações são mais coerentes e objetivas, embora estas ainda não sejam da mesma forma que o pensamento conceitual. Na linguagem dos adultos persistem alguns resíduos do pensamento por complexo, quando se usa o nome de família para classificar indivíduos, de forma similar como as crianças o fazem para classificar objetos. Outrossim, os jovens em formação, podem descrever e explicar conceitos para os quais não foram ensinados satisfatoriamente na escola, como no caso de ser vivo/célula.

Uma maneira eficiente para auxiliar na superação de tais dificuldades é a realização de aulas, atendendo à Zona de Desenvolvimento Proximal (ZDP) dos estudantes, também chamada de Zona de Desenvolvimento Imediato (ZDI). É valorizada nessa perspectiva, a relação entre o que o aluno sabe (Zona de Desenvolvimento Real-ZDR) e pode realizar mediante o ensino para chegar ao novo patamar de conhecimento ou ZDR.

Os conceitos não se formam pela interação das associações entre os objetos e sim por uma operação intelectual em que todas as funções mentais elementares participam de uma combinação específica. Essa operação é dirigida pelo uso das palavras como meio para centrar ativamente a atenção, abstrair determinados traços, sintetizá-los e simbolizá-los através de um signo (VYGOTSKY, 1991; 2010).

Para este trabalho é importante à diferenciação entre o conhecimento espontâneo e conhecimento científicos, como parte do desenvolvimento conceitual do ser humano. Os conceitos espontâneos estão ligados à experiência de vida, são assistemáticos, empíricos e de uso não intencional, têm fraca generalização, são usados do particular para o geral, são base para introdução do conceito científico, não são conscientes e são orientados para o objeto representado e não para o ato de pensar. Os conceitos científicos são aprendidos sistematicamente, mediante operações lógicas e abstratas, apresentam boa generalização, estão relacionados à experiência transmitida intencionalmente, são usados do geral para o particular, são base para a consciência, generalização, sistematização dos conceitos espontâneos (VYGOTSKY, 2000, p. 265-269).

A pesquisa sobre estrutura e funcionalidade de seres vivos enfatiza, nas suas várias fases, os conteúdos e os processos (as formas) de conhecimento dos alunos evidenciados nas tarefas planejadas e desenvolvidas pelos professores do Curso de Engenharia de Pesca. Os alunos mais velhos tendem a apresentar um desenvolvimento conceitual mais avançado em relação aos mais novos por conta das vivências sociais e escolares que contribuíram para a sua aprendizagem. Entretanto, ao considerar os alunos mais velhos submetidos a vários contextos 
novas) e maior escolaridade, as dificuldades de assimilação dos conteúdos podem ser comuns.

Para fins de averiguar os conhecimentos adquiridos sobre ser vivo/célula pelos alunos do ciclo básico do curso de engenharia de pesca, Campus XXIV, Xique-XiqueBA, mediante o ensino de disciplinas afins, adotamos a compreensão de conceito em rede, em que um conceito central poderá derivar muitos outros conceitos, conforme a orientação de Vygotsky $(1991,2010)$ acerca da formação conceitual. Neste sentido, podemos citar os trabalhos de Moura (2000) em relação aos conceitos de seres vivos em curso de formação com jovens e adultos, Hoese e Casem (2007) acerca da estrutura e função celular, Castro (2010) e Castro (2014) sobre conceitos de ser vivo/célula, assim como as pesquisas realizadas por Shaefer (1979) e Caballer e Giménez (1993) sobre o conceito central da função vital "crescimento de seres vivos", tendo vista a biologia celular. Por outro lado, devemos assinalar que autores como Jiménez-Aleixandre e Díaz-Bustamante (1993); Zamora e Guerra (1993); Bahar, Johnstone e Hansell (1999), Tekka Ya, Özkan e Sungur (2001); Yorek, Sahin e Aydin (2009) e Yorek, Sahin e Ugulu (2010) relatam as dificuldades que os estudantes têm em relação aos referidos conceitos biológicos e sua derivação.

Com base em Shaefer (1979) e Castro (2014), alguns conceitos/termos de biologia são centrais, pois funcionam como núcleo a partir do qual outros conceitos podem estar associados ou serem formados (derivados). Como exemplo dos primeiros, temos vida, ser vivo, crescimento, reprodução, sangue...; quanto ao segundo, citamos célula, divisão celular, nutrientes, gametas, hemoglobina etc.. Shaefer (1979) afirma que o conhecimento dos alunos sobre o conceito de crescimento de plantas aumenta com escolaridade, enquanto diminui para o crescimento de animais. Este autor associa tal questão á maior importância que é dada aos conteúdos de plantas em relação ao de animais nas aulas deste nível de ensino. Inferimos que a associação que os alunos fazem entre os fenômenos/objetos e os conceitos centrais/primitivos são fundamentais para elaboração de conceitos derivados. Podemos admitir, pela razão exposta, que a formação destes conceitos de animais em relação às plantas seja reduzida.

Segundo Yorek, Sahin e Ugulu (2010), a maioria dos estudantes universitários representa a célula por dois círculos concêntricos (membranas plasmática e nuclear), admitindo uma variedade de componentes. Eles representam a célula por meio do modelo de ovo frito ("fried-egg model"), sendo este uma barreira para a compreensão dos alunos acerca da diferenciação celular e outros conteúdos com este correlacionados.

Discordando da visão defendida por Shaefer (1979), estes autores informam que os conteúdos de células animais aparecem mais nos livros didático da escola básica, por isso, eles representam (desenhos) mais essas células (75\%) do que as células vegetais (25\%), incluindo a forma redonda $(48,7 \%)$ e retangular $(36,3 \%)$ e outros (15\%). Para eles, há uma representação que traz diferenças enormes entre os alunos do Ensino Fundamental e Médio em relação aos componentes da célula, mas no que se refere aos dados escritos, ocorre uma diferenciação pouco expressiva. Yorek, Sahin e Ugulu (2010) afirmam que, por exemplo, 75\% dos estudantes do Ensino Médio reconhecem a célula como unidade básica da vida e do ser humano/corpo humano, mas muitos deles podem não ter a compreensão básica de como funciona as referidas estruturas. Para estes autores, os avanços na integração funcional devem começar desde cedo com células, estruturas químicas 
e celulares (organelas) para que os estudantes avancem na escolaridade posterior com a compreensão dos conceitos na área, sendo que para isto, entendemos que a escola precisa iniciar um bom ensino de conceitos primitivos. Para eles, a derivação conceitual e maior para os conceitos de animais em relação ao conceito de plantas.

Segundo Jiménez-Aleixandre e Díaz-Bustamante (1993) é esperado que os jovens apresentassem um melhor conhecimento sobre células no Ensino Médio e Universitário do que no Ensino Fundamental. Este saber pode ser evidenciado através de desenhos em 2D/3D, das falas e/ou escrita dos alunos. Os estudantes apresentam respostas em 2D para questões mais gerais e em 3D para questões mais específicas. Isto pode estar associado, a exigência do enunciado para que eles organizem mais elementos conceituais para a elaboração da resposta gráfica. Um destes elementos conceituais é o volume, que possibilita um entendimento mais relacional da estrutura celular, o qual pode ser associado a uma melhor caracterização das estruturas internas da célula pelos estudantes com mais idade. Por isto, a idealização de um modelo de célula padrão é mais coerente no Ensino Médio e Universidade.

Ainda conforme estes autores, os estudantes de graduação, embora selecionem um modelo de célula em 2D (desenham), ao contrário dos secundaristas (3D), eles descrevem e usam uma célula como tal representação com mais riqueza de detalhes. Contudo, a representação dos elementos internos da célula é crescente no Ensino Médio e Universidade em relação ao Ensino Fundamental. Eles conhecem bem a função das organelas, mas misturam a forma delas (mitocôndria, complexo de golgi, vacúolo, ribossomo...), sendo que poucos enriquecem com detalhes as organelas com dupla membrana (mitocôndria e cloroplasto), bem como ordenam tais estruturas em seus devidos espaços dentro da célula.

No geral, no Ensino Médio, os alunos fazem uma boa descrição de todas as organelas da célula, incluindo o núcleo, membrana, e, às vezes, algum tipo de reforço externo, representando-a em 3D. Entretanto, a representação da célula por meio do modelo do ovo frito ainda é frequente em muitos países. A disparidade na representação celular em 3D na Espanha (52\%), por exemplo, contra $3 \%$ em outros países é minimizada na compreensão que os alunos fazem nesses últimos países, ficando de $21 \%$ para o primeiro e $19 \%$ para os segundos. Inferimos que o livro e materiais didáticos falham na explicação dos modelos de membranas e demais estruturas celulares, incluindo a célula como um todo (GIMÉNES \& DÍAZ, 1993).

Percebemos que os alunos avançam na descrição das organelas, mas não conseguem associar devidamente o nome à estrutura desenhada, bem como a compreensão que fazem para o funcionamento celular e/ou do organismo. Acreditamos, por isso, que um trabalho prático viabilizado com o microscópio associado à funcionalidade das organelas da célula, ampliar a amostragem dos tipos de células, associando o conhecimento obtido à resolução de problemas práticos e do cotidiano poderá suscitar um melhor êxito na apropriação conceitual dos alunos em diferentes níveis escolares acerca da célula/ser vivo.

Hoese e Casem (2007), numa pesquisa com alunos do Curso de biologia da as imagens construídas por eles sobre estrutura e função celular podem indicar o 
que eles sabem ou o que eles não sabem sobre os fenômenos biológicos dessa área. Para eles, os adolescentes conectam órgãos dentro de um sistema funcional, sendo que têm uma compreensão básica visual acerca do conceito, e, por isso, podem desenhar corretamente a célula de acordo com o livro didático, mas pode apresentar falhas na descrição da estrutura dela. Por dificultar a resolução de problemas reais ou aplicação dos conceitos em contextos teóricos, os conhecimentos espontâneos dos alunos indicam uma ponte para a construção do raciocínio lógico deles, pois eles usam o conhecimento dentro de um sistema de conhecimento. Para tal, se remete a importância de o professor fazer correção nas formas de pensamento destes alunos para que eles ampliem o repertório de resposta para os fenômenos estudados dentro de um sistema de conhecimento ou rede conceitual.

Para Hoese e Casem (2007) e Jiménez-Aleixandre e Díaz-Bustamante (1993), os desenhos produzidos pelos alunos universitários e do Ensino Médio podem indicar o nível de conhecimento acerca de estrutura e funcionalidade celular num nível mais geral ou representar um conceito mais específico de acordo com ensino ministrado pelo professor. Para os primeiros autores, as imagens feitas pelos estudantes podem ser insuficientes (expressas corretamente, mas com incompleta informação), incorreta e icônica (reprodução do livro texto).

Tekaia, Okzan e Sungur (2001) afirmam que a maioria dos estudantes de Ensino Médio tem dificuldades na compreensão dos assuntos mitose e meiose pela razão de serem conteúdos abstratos e terem terminologias complicadas (cromossomo, DNA, alelos, gene, cromátide...). Eles memorizam termos e não fazem distinção correta deles, acabando não os assimilando devidamente. Por não dominarem os conceitos básicos (composição química, reação química), eles têm dificuldades em compreender assuntos como fotossíntese e respiração; por não conhecer osmose/difusão não compreendem a excreção (filtração tissular). Eles não aprendem conceitos que demandam uma interação funcional e que atuam dentro de um sistema; para compreender pressão e velocidade do sangue, por exemplo, precisa antes saber o que é sangue em sua composição e propriedades principais, dar importância à difusão nos capilares e como se organiza o sistema circulatório.

Para Tekaia, Okzan e Sungur (2001), os conceitos mais difíceis de serem assimilados pelos alunos são hormônios, genes e cromossomos, mitose e meiose, sistema nervoso, genética mendeliana, síntese de proteínas e respiração. Estes são conteúdos da biologia de Ensino Médio que, para ser ensinados, dependem de conhecimentos básicos que deveriam ser ensinados aos alunos na escolaridade anterior: forma, composição e tamanho dor organismos, propriedades vitais etc. Estes autores afirmam que a visão dos alunos é pouco ampliada na escolaridade que segue por falta de interesse e aptidão, a natureza abstrata dos temas, as diferenças de significados para os termos e a falta relação causal nos livros, o que Ihes levam a uma dificuldade na compreensão dos referidos assuntos.

Além dos conteúdos complexos ora relatados, assuntos de biologia básica como célula, organelas, transporte de nutrientes, órgãos, processos físicos, trocas gasosas, estrutura e função de seres vivos apresentam dificuldades para estudantes universitários. Com base em Bahar, Johnstone e Hansell (1999), as dificuldades referentes a conteúdos básicos como transporte e absorção de nutrientes pela célula são facilmente superadas pelo ensino, quando voltado para esta área conceitual. Por outro lado, os conceitos como crescimento de seres vivos 
(animais e plantas), divisão celular, digestão, genes, herança demanda uma atenção especial e intensiva para o ensino pelos seguintes motivos: os alunos compreendem as informações transmitidas pelo docente, mas não assimilam o significado de como funciona o conceito; eles reclamam do caminho metodológico adotado pelo professor que torna o assunto difícil e do tempo que não é suficiente para assimilação das informações ensinadas. Acreditamos que ensinar aos alunos mediante a função dos conteúdos, principalmente buscando uma relação com o dia a dia, poderá ser uma ferramenta útil para minimizar as dificuldades de aprendizagem em sala de aula, a exemplo de relacionar alimentação, digestão, absorção, transporte e papel das organelas e função vital.

Por outro lado, cabe assinalar que os alunos em geral não reconhecem a falta de estudo e motivação como sendo uma das causas para não apropriação dos conteúdos em sala de aula. Para Teixeira (2004), Castro (2014) e Mohapatra e Mohapatra (2014), tornar visível os fenômenos biológicos não observados e experimentados para os alunos é um desafio para o professor, sendo que para este último autor, o uso de animações pode ampliar a representação (desenho) estrutural e funcional da célula por eles, especialmente para assuntos específicos.

Para Zamora e Guerra (1993), a dificuldade dos alunos, quanto à assimilação dos conteúdos de célula e suas funções, deriva da concepção que eles têm sobre a célula como entidade isolada, a qual não funciona em miniatura como um organismo multicelulado, muito menos exercem uma atividade interativa dentro de um sistema complexo. Por esse motivo, custa os alunos aceitarem que as células como seres vivos que respiram, digerem e reproduzem para manter seu ciclo vital de maneira similar como os organismos pluricelulares realizam. Estes autores relatam que os alunos confundem o tamanho de células com o tamanho do organismo, moléculas, já que eles são menores do que um grão de areia. Eles distinguem o núcleo do citoplasma, mas confundem ainda membrana plasmática com a parede celular; ainda descrevem pobremente as organelas. Essa questão é mais problemática quando eles não concebem que a célula é independente em se tratando de organismo unicelular (bactéria, fungo, protozoário...), sendo dependente diretamente de outras, dentro de um tecido, órgão, ou de um sistema vivo, considerando os fatores que interferem no seu funcionamento (nutrientes, temperatura...).

Zamora e Guerra (1993) discutem questões básicas da biologia celular que estão associadas aos fenômenos cotidianos são estrutura da célula/organismo, herança, reprodução, crescimento, metabolismo, diferenciação celular e organização dos sistemas orgânicos (célula a sistema). Neste sentido, eles afirmam (p.4) que os alunos da escola secundária concebem que,

são feitos de células e receberam as células do pai o da mãe ou apenas as receberam antes de nascer; as células desaparecem ao nascer, novas células nascem com eles e são distribuídas pelo corpo [...] Elas também crescem quando crescemos [...] As células apresentam estágios de crescimento como as pessoas apresentam [...] As células necessitam nascer para viver, comer, de sangue, de alimento e exercício físico, a gente deve comer bem para sermos saudáveis [...] Elas usam o alimento e respiram para viver, ficar forte, para multiplicar elas mesmas, ajudar a crescer [...] Os organismos são diferentes por que tem diferentes células, ou diferente funções, mas não informam a nada a respeito da herança genética [...] As células se reproduzem 
relacionada à regeneração do corpo (ferimento, cicatriz) [...] Elas funcionam juntas para não morrer, porque elas têm cérebro e coração [...].

Pode se admitir pelo exposto que a imagem de célula é muito obscura para a maioria dos estudantes do Ensino Médio. É mais fácil para eles conceberem que o corpo produz suas próprias células, tendo o cérebro e o coração controle por sua organização no corpo (visão dominante).

Os alunos do Ensino Médio apresentaram respostas espontâneas para estas questões, muitas vezes, amparadas no finalismo, bem como usam a função para responder aos questionamentos os quais exigem respostas referenciadas num nível científico. Como não têm referentes concretos como apoio às suas respostas, eles se servem da imaginação para explicar os fenômenos/eventos os quais são solicitados, com base no livro didático. Zamora e Guerra (1993) sustentam que como forma de suprir tal dificuldade, os alunos usam a referência indireta apresentada como explicação em sala de aula pelo professor para as questões emergidas no contexto de sala de aula. Desta forma, a concepção animista desses alunos precisa ser substituída por uma visão sistêmica atual acerca do organismo/célula (lago como ecossistema) numa relação com outros sistemas funcionais que exige participação do papel vital de organismos de tamanhos e estruturas diferentes, envolvendo variáveis diversas (espécie, anatomia, nutrição, alimento...), por conseguinte possibilitando desenvolver novos e melhores conhecimentos nos alunos.

Yorek, Sahin e Aydin (2009) afirmam que os estudantes de Ensino Médio usam parâmetros animistas e antropocêntricos, como concepção de ser vivo/vida. Eles usam tal princípio para auxiliar na identificação/classificação de animais e plantas e também de organismos menores. Como há falta de experiência com seres vivos pequenos na vida cotidiana (microscópio) e os aspectos de beleza, importância, habitat e movimento não são bem firmados na cognição humana para estes seres vivos, acreditamos que dai reside à dificuldade de caracterização e de reconhecimento deles. Acreditamos que isto pode repercutir num menor conhecimento dos alunos da escola secundária e universidade em relação ao organismo/célula.

Dentre uma série de aspectos relacionados ao crescimento de seres vivos (especialmente animais e plantas) e na sua relação com o referente concreto, os alunos do Curso Superior de Biologia, por exemplo, apresentam pouco desenvolvimento em comparação aos de Ensino Médio. Neste sentido, os estudos de Shaefer (1979) mostram que os alunos usam como referente concreto, a medida geométrica, movimento, tamanho e fatores econômico, sociais e psicológicos quase em igualdade com a diferenciação celular, desenvolvimento, divisão celular e reprodução, hormônios e herança genética. Isto significa que a função biológica de crescimento está atrelada a um sistema interno estendido e depende externamente das condições do meio. Por outro lado, em grande medida, percebemos que os aspectos físicos (tamanho, forma...) apresentados por estes alunos representam uma visão espontânea para a referida função a qual não foi desenvolvida no nível científico nos níveis de escolaridade referenciados.

Seguindo as Orientações Curriculares Estaduais para o Ensino Médio (BAHIA, 2005), Castro (2010) afirma que a criança compreende os conceitos gerais, Página | 308 envolvendo seres vivos, o corpo humano e sua funcionalidade. No Ensino Médio e universidade, este domínio conceitual deveria se alargar em nível das suas 
especificidades quanto à participação e entendimento destes alunos nos debates contemporâneos. Castro (2010) relata o ensino de ciências no Ensino Médio como introdutório, disciplinar, o que nega a possibilidade de avanço conceitual nessa referida área de conhecimento. Segundo ele, pesquisas mostram que os conteúdos de seres vivos/célula possibilitam uma maior integração entre os conhecimentos de ciências naturais e a relação entre sociedade e ciência contemporânea. Isto apoia a tese de que são assuntos que podem potencializar ou viabilizar o ensino de conceito científico na escola básica e na universidade, considerando que estes fazem parte do contexto de vida imediato das pessoas. Para isto é preciso conhecer o ponto de vista dos alunos acerca da relação do uso do conhecimento científico para explicar questões cotidianas e também do espaço de formação profissional, como no caso do trabalho realizado na UNEB, Campus XXIV.

\section{3- METODOLOGIA}

\subsection{Pressupostos}

O trabalho de levantamento de dados na UNEB, Campus XXIV foi desenvolvido com base na orientação do método dialético. Para tal, mencionamos três fases do método dialético de construção do conhecimento escolar: prática-teoria-prática partindo do nível de desenvolvimento atual dos alunos, trabalhando na zona de desenvolvimento imediato, para chegar a um novo desenvolvimento atual. Essas fases são definidas a partir dos passos a seguir:

1) O primeiro passo é a Prática Social Inicial do conteúdo ou do conceito que se expressa pela vivência cotidiana na totalidade empírica;

2) O segundo passo é a Teorização que consiste na explicitação da dimensão científica do conteúdo ou do conceito, ou seja, é o estudo do conhecimento historicamente produzido e sistematizado;

3) O terceiro passo é o retorno à prática, agora como Prática Social Final do conteúdo, que deverá ser usado para a transformação da realidade (GASPARIN 2007, p.9).

Iniciou-se o trabalho investigativo no nível de desenvolvimento atual ou Zona de Desenvolvimento Real (ZDR) dos alunos (conhecimentos espontâneos e escolares), com base num diagnóstico de pesquisa realizado sobre ser vivo/célula na UNEB; seguimos com a Zona de Desenvolvimento Proximal (ZDP) ou Imediata a partir das aulas ministradas pelos professores (as) com a turma (2014/2015), sendo que se tomou como ponto de partida nesse período, uma nova Zona Desenvolvimento Real com as novas atividades de sala de aula desenvolvidas com os alunos (GASPARIN, 2007). Visamos, com isto, a atender aos novos conceitos adquiridos por eles em relação às aulas realizadas pelos professores (as) da UNEB.

A partir do diagnóstico adquirido na primeira etapa da pesquisa', descrevemos a prática inicial dos conteúdos proposta por Gasparin (2007). Este foi usado como base para compreensão dos avanços dos conhecimentos dos alunos em relação à prática desenvolvida pelos professores no semestre atual e seguintes (1 ao 3 ). 
As aulas ministradas pelos professores (as) referenciaram a teorização dos conteúdos e os novos conceitos trazidos pelos alunos, enquanto e o uso deles para responder questões fora da universidade que estão relacionadas aos conteúdos acadêmicos representou uma prática final dos conteúdos.

\subsection{A pesquisa qualitativa}

Usamos a pesquisa qualitativa vinculada a entrevista semiestruturada (ese1) no levantamento de dados acerca da identificação dos conhecimentos dos alunos sobre os conceitos de ser vivo/célula. A abordagem qualitativa poderá permitir ao pesquisador ir além da superfície dos eventos, determinar significados, muitas vezes ocultos, interpretá-los, explicá-los e analisar o impacto na vida em sala de aula (BOGDAN e BIKLEN, 1994).

A coleta de dados envolveu 8 alunos do 3을 semestre do Curso de Engenharia de Pesca da UNEB-Campus XXIV, matriculados no período 2014.1. Para tal, efetuamos uma entrevista semiestruturada (ese1) com esses alunos, tendo $1 / 2$ hora aproximada para cada aluno. As entrevistas foram gravadas em áudio e transcritas pelos bolsistas de iniciação científica e voluntários, sendo que as transcrições foram validadas pelos entrevistados (BOGDAN e BIKLEN, 1994). Os dados referentes aos desenhos elaborados pelos alunos foram fotografados.

A realização das entrevistas semiestruturadas ocorreu na sala do Núcleo de Estudo e Pesquisa Ambiental (NEPEA)- Departamento de Ciências Humanas e Tecnologias- DCHT/Campus XXIV, conforme cronograma previamente combinado com os sujeitos da pesquisa.

Os conteúdos usados para a composição da entrevista foram estrutura e função celular. Eles foram organizados com os seguintes aspectos: célula, diferenciação celular, crescimento, respiração, reprodução, alimento/nutriente, herança, unidade e hábito de vida.

Com base em Triviños (1987), foram elaboradas perguntas básicas para fins de atender aos objetivos da pesquisa, vinculadas à vertente teórica históricocultural (dialética). Nessa linha, as perguntas podem ser designadas como explicativas ou causais. $\mathrm{O}$ objetivo desse tipo de pergunta seria determinar razões imediatas ou mediatas do fenômeno social. Ainda com base neste autor, consideramos perguntas imediatas como: "Desenhe uma célula com detalhe e explique? O que uma célula necessita para funcionar, e você?" Em relação às perguntas mediatas, podemos citar: "O que acontece com sua célula quando você cresce? "Qual o funcionamento da célula enquanto você come e respira?" As questões que exigem respostas imediatas são geralmente estruturais, enquanto as que suscitam respostas mediatas são funcionais.

Segundo Miles e Huberman (1994), a análise de dados tem como objetivo dar sentido aos dados coletados, apresentando resultados e levando conclusões para o estudo. Por isso, buscamos verificar os conceitos dos alunos após as aulas ministradas pelos professores (as) nos três primeiros semestres de curso.

Os dados coletados foram analisados de modo que as respostas dos alunos foram agrupadas em categorias conceituais e comparadas. Para isto, consideramos que os conhecimentos levantados refletem a relação dos conteúdos/conceitos que se expressam a teorização que consiste na explicitação da dimensão científica do 
conteúdo ou do conceito, ou seja, é o estudo do conhecimento historicamente produzido e sistematizado.

\section{4- O CONHECIMENTO SOBRE SER VIVO/CÉLULA DOS ESTUDANTES DO 3 SEMESTRE DO CURSO DE ENGENHARIA DE PESCA DA UNEB}

Tendo como base o levantamento de dados empírico (questionário) sobre conhecimentos prévios (ser vivo/célula) dos alunos ingressos no curso de engenharia de pesca, no período 2014.1, buscamos identificar e analisar os conceitos mais específicos (célula, diferenciação celular, crescimento, respiração, reprodução, alimento/nutriente, herança, unidade e hábito de vida), envolvendo a estrutura e funcionalidade do organismo/célula. Para isto, foram considerados os conceitos científicos e espontâneos em 2 dimensões: a estrutura e a função, podendo cada conceito abranger a estrutura e a função simultaneamente, a partir das seguintes questões: 1 - Desenhe uma célula com detalhe e explique; 2ㅇ- Como você acha que é uma célula? Explique; 3-. O que acontece com sua célula quando você cresce?; 4-. O que uma célula necessita para funcionar, e você?; 5ㅇ- Qual o funcionamento da célula enquanto você come e respira?; 6-- Se seus órgãos são feitos de células porque elas são diferentes?; 7ํ-- Como as células se reproduzem?; 8-- Qual a relação da reprodução da célula com a formação de novos organismos?; 9o- Se você tem diferentes células como estas trabalham juntas como unidade?; 10-- Qual a relação do seu hábito de vida diário com o funcionamento celular? E com seu organismo? (Gráfico 1).

Figura 1- alunos do 3ㅇ semestre do curso de Bacharelado em Engenharia de Pesca

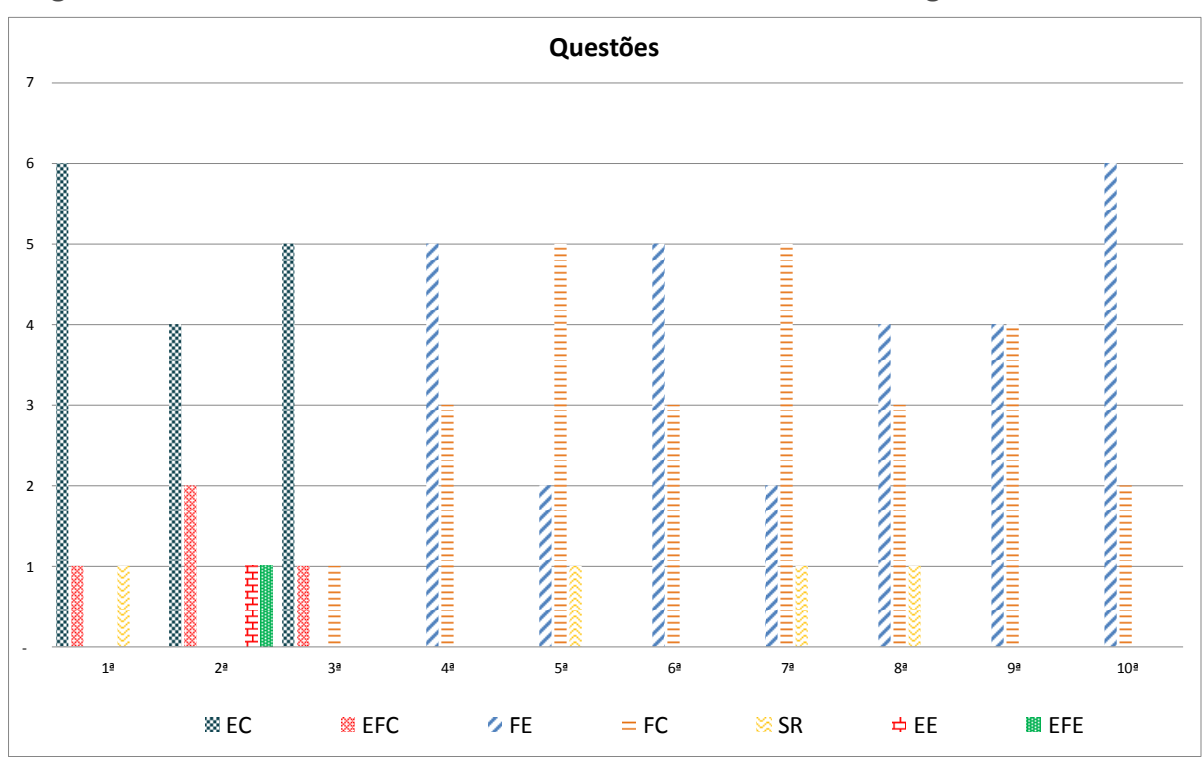

E.C- Estrutural Cientifica, E.F.C- Estrutural Funcional Cientifica, F.E- Funcional Espontânea, F.C- Funcional Cientifica, S.R- Sem Rendimento, E.E- Estrutural Espontânea, E.F.EEstrutural Funcional Espontânea.

Uma resposta estrutural envolve aspectos físicos de seres vivos/célula como membrana, citoplasma, núcleo, nutrientes, organelas ou anatomia e morfologia de indivíduos multicelulados. A resposta funcional se relaciona com as funções das organelas ou estruturas de organismos macroscópicos, podendo, em ambos os 
casos, serem espontânea ou científica, de acordo com a origem e desenvolvimento de tais formas de pensamento (dia a dia ou na escola/universidade).

Para as primeiras três questões, houve respostas com conceitos científicos estruturais em sua maioria (6, 4 e 5 E.C, respectivamente; 1 , 2 e 1 E.F.C, respectivamente), uma minoria para espontâneo (1 E.E e 1E.F.E para a 2a questão), mas apenas uma funcional científica (1 F.C para 3a questão) e 0 (zero) funcional espontânea. Para as demais questões, houve respostas apenas funcionais, tanto no nível científico como espontâneo, sendo 5, 2,5,2,4,4, 6 F.E para questões 4 a a 10 a respectivamente; 3,5, 3, 5,3,4,2 F.C para as questões mencionadas. Para algumas questões, não houve rendimento (S.R para a 1a $, 5 \underline{a}, 7$ e 8 a questão, respectivamente).

A partir dos conceitos estruturais emergem os conceitos funcionais (E.F.C), mas para os conceitos funcionais não encontramos correspondência em nível estrutural, ou seja, nas proposições conceituais estruturais aparecem termos funcionais, enquanto nessas não aparecem características do conceito estrutural. Isto nos faz inferir que a funcionalidade pode contribuir para mobilização do pensamento do aluno para formação do conceito científico no âmbito estrutural. Neste sentido, um conceito derivado como o de célula/organismo humano, por exemplo, para assimilado pelos estudantes, depende de estratégias de ensino que envolva experimentos, observação microscópicas, as quais eles não tiveram oportunidade de vivenciar.

As respostas para as categorias E.C e E.F.C para a primeira e segunda questão respectivamente "desenhe uma célula com detalhe e explique?" e "como você acha que é uma célula, explique?" podem ser separadas em 3 tipos: desenhos com respostas sem nominação/descrição das organelas; desenhos com nome das organelas, mas sem descrição delas e só desenhos sem descrição funcional das organelas.

Com base em Hoese e Casem (2007), afirmamos que as imagens (fig.1a, $1 b, 1 c)$ são insuficientes, pois não apresentam informações que denotam a caracterização básica de uma célula (membrana/reforços e organelas).

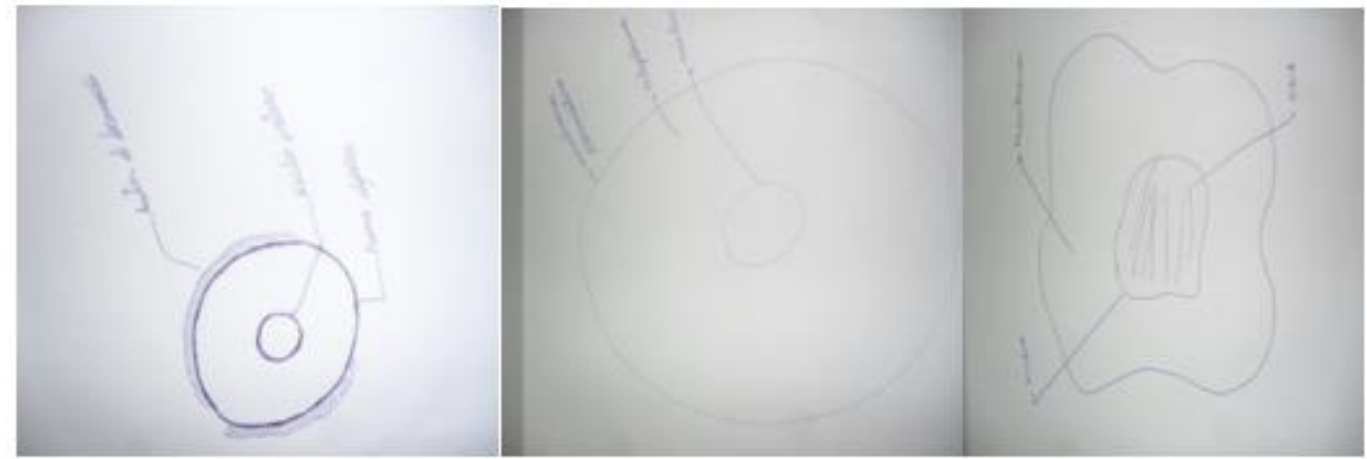

Para os referidos autores, as figuras (2a, 2b, 2c e 2d) são expressas corretamente, mas com incompleta descrição, devido conter informações básicas, mas não avançar na descrição da célula e/ou nominação das organelas. Para eles, tal representação também é insuficiente pela razão exposta. Contudo, 
discordamos destes autores porque os desenhos dos alunos refletem uma reprodução do livro texto feitos em sala de aula pelos professores (representação icônica). Eles conhecem bem a função das organelas, mas misturam a forma delas (mitocôndrias, complexo, vacúolo, ribossomos...), sendo que poucos enriquecem com detalhes as organelas (dupla membrana), bem como ordenam tais estruturas em seus devidos espaços dentro da célula.

Figura 2a- aluno A4

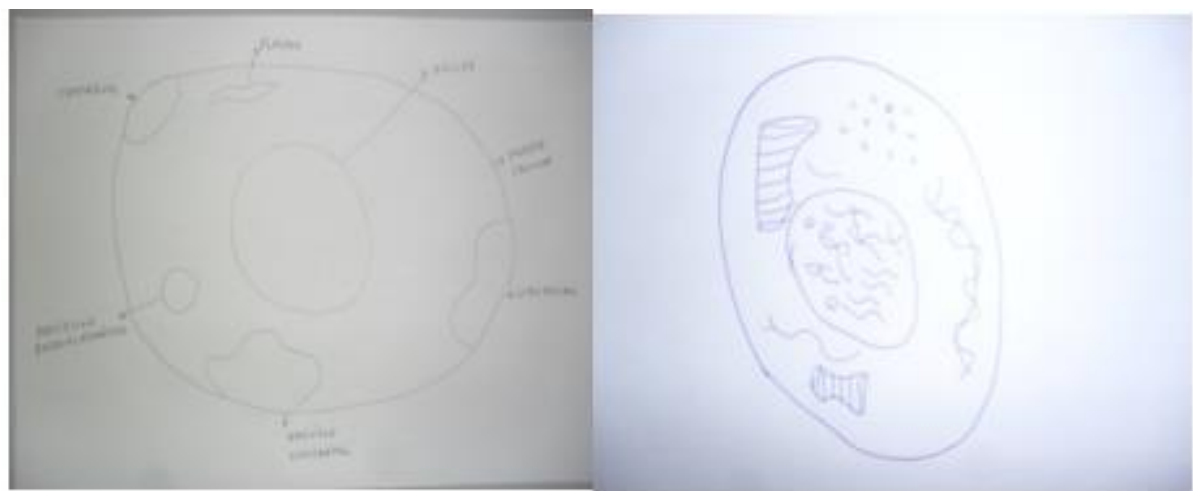

Figura 2c- aluno A7

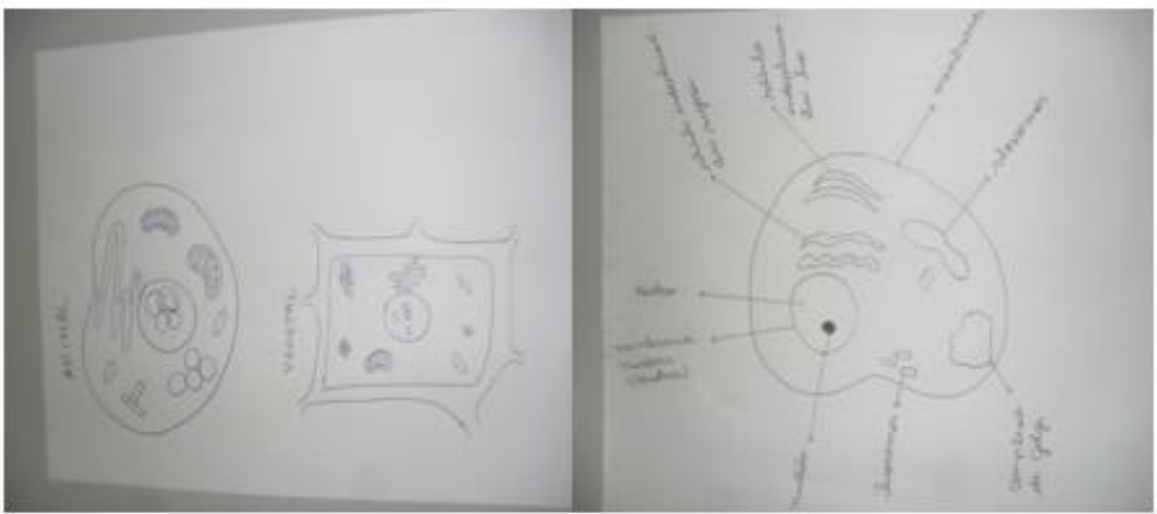

A figura 3 denota uma imagem icônica típica (reprodução do livro texto), pois o aluno reproduz as figuras do livro texto, mas não avança na descrição funcional da célula/organelas. 


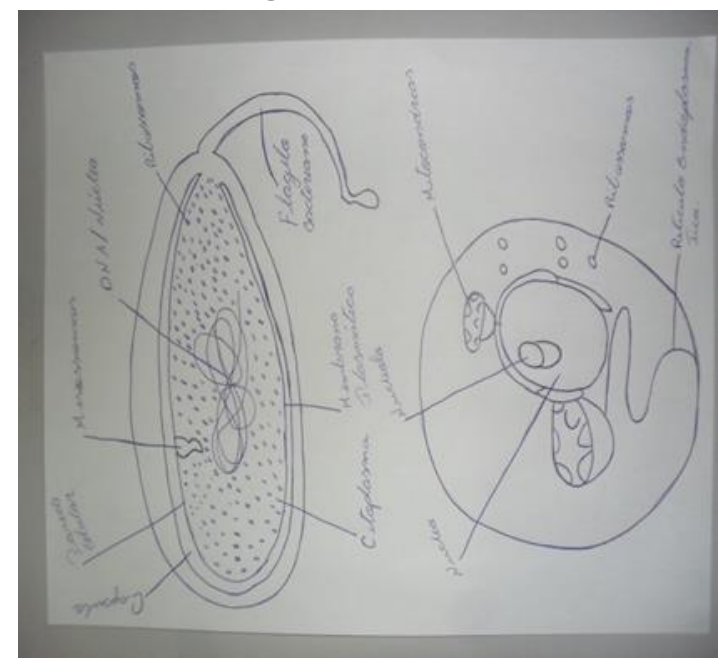

Os conceitos contidos nas categorias estrutural espontâneo (E.E) e estrutural funcional espontâneo (E.F.E) para segunda questão estão no limite entre o conhecimento espontâneo e a ausência de conhecimento (categoria S.R), pois os estudantes não conseguem referenciar a célula nem por uma função específica ou geral, nem por exemplos concretos. Em especial, as respostas no nível estrutural funcional espontâneo sinalizam um conhecimento limítrofe, próximo do pensamento por complexo, pois o aluno quando questionado, não consegue emitir nenhuma explicação que perpasse a estrutura do objeto/fenômeno (VYGOTSKY, 1991; 2010).

Com base em Castro (2014), para assuntos que os sujeitos não apresentam referentes concretos, a instrução funcional em sala de aula poderá auxiliar os alunos a iniciarem a elaboração de formas pensamento mais próximos do conhecimento científico. Isto pode ser desenvolvido mediante exemplificação das funções macroscópicas do organismo humano e sua relação no aspecto microscópico (alimentação, trocas aéreas, respiração pulmonar e respiração celular). Esclarecendo tal questão, podemos citar que o oxigênio inspirado chega aos pulmões e deste segue para coração onde é bombeado para todo organismo/célula; o gás carbônico derivado da digestão dos nutrientes na célula é lançado no sangue sendo que o coração o transporta para o pulmão onde é trocado pelo oxigênio e expirado. Neste sentido, estaremos tornando visíveis os eventos biológicos (científico) no seu aspecto cotidiano como forma de superação da visão animista/antropocêntrica sobre ser vivo/vida que limita o crescimento conceitual dos alunos na referida área de conhecimento (SHAEFER, 1979; TEIXEIRA, 2004; YOREK, SAHIN \& AYDIN, 2009; MOHOPATRA \& MOHOPATRA, 2010; CASTRO, 2014).

De acordo com Yorek, Sahin e Ugulu (2010), cabe assinalar que os desenhos acima são influenciados pelo livro didático de 2 formas: para primeira tipologia, o modelo de ovo frito (círculos concêntricos), sem evidenciar a estrutura e função das organelas; para a segunda e terceira tipologias, o modelo 2D representa a estrutura da célula de forma limitada, ou seja, a disposição e descrição das organelas, tendo ampliação em tal caracterização na última figura (3). Os alunos, em geral descrevem as células em seus aspectos gerais, conforme denominado abaixo: 
A1- Eu acho que uma célula com varias coisas dentro [...] A2-É uma estrutura esférica, microscopia com diversas estruturas que desempenham diversas funções diferentes e importantes como: lisossomos; reticulo endoplasmático liso e rugoso, plastos, núcleo, centríolos. A3-Tem formato arredondado, não pode ser observada a olho nu, por ser micro. A4- É uma estrutura que apresenta informações, porque tem funções no organismo vivo. A5Caracterizada por sua forma, por que vai auxiliar ela no processo de locomoção no meio em que vive o organismo [...] A6- Ela é microscópica, e exerce grande influência no funcionamento do todo (corpo). A7-É algo que possui uma maquinaria que pode ser ou não completo, mas que é a parte dela que se conhece o processo evolutivo. A8- É uma estrutura microscópica, que possui no seu interior material genético responsável pela reprodução celular.

Ao contrario do proposto por Jiménez-Aleixandre e Díaz-Bustamante (1993), mesmo para conceitos específicos como a primeira e segunda questão, os estudantes ilustram a célula em 2D, o que era esperado para aspectos mais gerais, como, por exemplo, para a o tamanho e forma da célula. Isto deve estar associado ao limitado domínio dos alunos sobre a biologia celular.

Em relação ao quesito 3, "o que uma célula necessita para funcionar, e você?", alguns alunos afirmam que enquanto se alimentam e respiram, usam os alimentos/nutrientes a fim de suster energia para o corpo desenvolver suas estruturas e funções orgânicas. Eles afirmam que a célula/ser vivo se serve das funções plásticas dos alimentos (reserva, preenchimento...), mas não relacionam tal questão com os trabalhos realizados no seu dia a dia (4 E.C, 1 E.F.C, 2 F.C e 1 E.E), como exposto a seguir:

EC- A1- Energia para funcionar as atividades químicas da célula; A3Necessitam de vitaminas essências á sua manutenção; A4- De vida, de produção de nutriente. A8- Para sobreviver, as células e os tecidos necessitam de uma organização metabólica interna, a qual carece da participação de enzimas, proteínas com propriedades de catalisadores químicos, nas características, de ativação especial entre elas a especificidade relativa ao (alto, media a baixa) reconhecimento dos seus substratos.

E.F.E- A5- Necessita que todos seus componentes funcionem corretamente, pois são dependentes uns dos outros.

F.C- A6- Necessitam de micronutrientes para serem metabolizados e transformados em ATP e ADP na sua respiração celular; os diversos nutrientes são utilizados de diversas maneiras para a sua sobrevivência [...] em funções estruturais e de reseva [...]

E.E- A2-Necessita de um meio propicio para desenvolvimento.

Os conceitos são mencionados pelos alunos A2 e A5 na sua superfície (espontâneo), enquanto A1, A3, A4 e A8 avançam na explicação científica acerca da referida questão. A1, A3 e A4 exemplificaram respectivamente, em entrevista complementar, sobre as atividades químicas celulares (respiração celular, sais minerais...), papel das vitaminas (A, B, C....) e diferentes nutrientes advindos do processo de digestão extracelular (vitaminas, proteínas, carboidratos...). O pensamento sistêmico e conceitual básico foi verificado em A6 quando este relaciona célula, DNA, RNA, enzimas, sistema nervoso, hormônio, destacando a autorregulação no controle das funções vitais, a exemplo do uso dos nutrientes pela célula/organismo. Este ponto de vista pode ser usado para explicar o 
funcionamento de células diferentes como unidade de um organismo multicelulado superior (ver questão 9).

Quanto a questão 4 "o que acontece com sua célula quando você cresce?", os alunos relacionam o fenômeno célula $x$ crescimento ao ciclo de vida ( 2 alunos), desenvolvimento e crescimento (2) de forma espontânea (F.E), divisão celular/multiplicação, hormônios, excreção, especialização, aumento do volume e organelas (4 alunos- F.C). A compreensão sistêmica é limitada para aluno, no que tange a associação entre hormônio, mitose, alimentação/nutrição, herança e crescimento dentro de um sistema que vai da célula para o organismo humano (SHAEFER, 1979; CABALLER \& GIMÉNEZ, 1993; MOURA, 2000; HOESE \& CASEM, 2007; CASTRO 2010; CASTRO, 2014). Entretanto, com base Jiménez-Aleixandre e Díaz-Bustamante (1993), podemos afirmar que eles reconhecem uma interelação morfofuncional, explicada pela ação de nutrientes movida pela liberação de substâncias específicas na célula/ser vivo. O aluno A4 inicia tal explicação sistêmica argumentando que a regulação do crescimento da célula/organismo ocorre mediante sais e vitaminas, mas não que os nutrientes exercem papeis distintos concomitantes (reserva, regulação...) e que isto está relacionado ao crescimento.

Relacionando alimentação, digestão, nutrição e respiração, para a questão 5 "qual o funcionamento da célula enquanto você come e respira?", o número de respostas para os conceitos científicos foi menor do que para os conceitos espontâneos: 3 F.C, 1 S.R e 4 F.E. Para os primeiros, percebemos uma incompletude conceitual nos alunos, mas sinalizando avanços no nível do pensamento conceitual, como exposto no excerto:

F.C- A4- Recebe nutriente, trabalha para que meu organismo funcione perfeitamente, atende as necessidades; A6- Transforma os nutrientes em energia durante a respiração celular. A7- Eles recebem nutrientes ingeridos pós digestão e oxigênio da respiração a partir de estruturas especializadas na captação de nutrientes [...] Complexo de golgi armazena e libera os nutrientes, a mitocôndria os usa na respiração e os lisossomos fazem a digestão intracelular.

Ademais, a explicação fica restrita ao campo da generalização mais básica que os alunos fazem com o assunto, como ilustra o trecho:

F.E- A1-Precisa de entrada e saída de nutrientes presentes no corpo. A2Quanto à alimentação devem funcionar na digestão e na respiração no processo de trocas de gases com o meio. A3- Em ambas os casos ela absorve parte dos itens através de outras organelas que trabalham em conjunto. A5Elas estão recebendo nutrientes do corpo, e liberando o que o corpo precisa [...] e assim auxiliando nas funções.

Um aluno acrescenta que os nutrientes servem para gerar energia e compor as estruturas do corpo (célula, tecido, órgão...) como meio de explicar o que ocorre com os nutrientes no corpo. Para ambos os exemplos, a explicação funcional pode ser usada como ponto de partida para explicar a estrutura das organelas celulares relacionadas à digestão e respiração celular (CASTRO, 2014). No primeiro exemplo, a funcionalidade é mais específica e no segundo, mais geral.

Para a questão 6- "se seus órgãos são feitos de células porque elas são diferentes?", o conceito de diferenciação celular é anunciado por alguns alunos (3 F.C) de forma não explicita auxiliado por um pensamento funcional a este relacionado, conforme ilustrado a seguir: 
A4- Porque elas são diferentes, mas trabalham em conjunto, as células do tecido ajudam a manter elasticidade, recupera derme quando sofre uma lesão, também nosso corpo é formado por partes diferentes. A6- Cada célula possui uma utilização e estrutura própria, ditadas pelo DNA, para uma função especifica. A7- Os órgãos são compostos de tecidos altamente especializados em funções específicas, por isso são diferentes...

A funcionalidade espontânea ( 5 F.E) expressa nas demais respostas para esse item, evidencia que o assunto não foi assimilado por eles na escolaridade anterior, mesmo se tratando de um conceito elementar na área de biologia (ZAMORA \& GUERRA, 1993). Por outro lado, por meio dos termos/frases funcionais expostas no trecho que segue pode indicar um ponto de partida para o ensino de biologia, seja para componentes curriculares que tratam funcionalidade organismos micro e macroscópicos, seja no componente curricular introdutório de biologia em cursos universitários (ZAMORA \& GUERRA, 1993; BAHAR, JOHNSTONE \& HANSELL, 1999; CASTRO, 2014):

A1-Elas são diferentes porque no momento da formação as células se dividiram em funções diferentes. A2- Porque cada célula tem sua função no organismo. A3- São diferentes para que cada uma realize uma função especifica diferenciada. Por que elas têm diferentes funções nos órgãos. A8Porque existe uma grande variedade de células, cada uma com sua especialidade.

Isto não resolve o problema da formação básica, mas possibilita uma nova oportunidade de os estudantes apreenderem conceitos não internalizados anteriormente, como suporte para sua formação profissional atual e futura.

Para Tekaia, Okzum e Sungur (2001), os conceitos de divisão celular mitose e meiose são considerados como os difíceis na área biológica pelo seu caráter abstrato e falta do uso de referente concreto em sala de aula pelo professor (vídeos, experimentos...). Com base nestes autores, o domínio dos conceitos de mitose e meiose (derivado) a partir dos conhecimentos prévios dos alunos é fundamental para que eles ampliem a compreensão do conceito central de reprodução, mas num nível mais elaborado, já que os referidos conceitos estão imbricados num sistema com diferentes níveis de generalização. Neste sentido, em relação à 7ạ questão "como as células se reproduzem?", 3 alunos apresentaram conhecimento funcional espontâneo (F.E) e 5 funcional científico (F.C), conforme expresso abaixo:

F.E- A2- Por partições, como se fosse de uma forma assexuada. A3- Se reproduzem a partir do ligamento de outras células. A4- Assexuada, por divisão celular.

F.C- A1- Mitose quando a presença de gametas masculino e feminino. [...] Há troca genética sexuada [...] Meiose as células se dividem sem troca genética assexuada. A5- De forma assexuada por mitose; A6- Através da meiose; A7Pela mitose e meiose. A8- As células se reproduzem através da duplicação de seus centríolos e posterior divisão em duas células filhas. [...] Através da mitose.

A proporção conceitual anteriormente expressa se manteve equiparável para 8 a questão "qual a relação da reprodução da célula (meiose) com a formação de novos organismos?" Os pontos de vista envolvendo a funcionalidade espontânea podem ser usados como ponto de partida para elaboração de formas de pensamento mais desenvolvidas pelos alunos do curso de engenharia de pesca, 
UNEB, Campus XXIV. Acreditamos que os conceitos estruturais científicos podem ser edificados a partir dos conceitos funcionais espontâneos (F.C), podendo ser o ensino da funcionalidade científica (F.C) usada como meio para tal questão, conforme o excerto abaixo:

F.E- A2- Porque terá ligação com a função nos organismos de acordo com o seu desenvolvimento de vida. A3- É que elas necessitam que outros organismos sejam derivados dessas células e assim repassam as características para as outras. A4- Porque elas se reproduzem rápido, basta o organismo passar a mensagem que precisava. A5- Porque as células morrem e novas células devem ser formadas para formar os órgãos e tecidos e assim sucessivamente.

F.C- A1- Na reprodução sexuada forma um outro indivíduo. Na reprodução assexuada forma o mesmo indivíduo. A6- Ela transforma-se através de meiose novos organismos. A7- Por mitose e meiose. A8- Assexuada: é um tipo de reprodução que ocorre sem intervenção de gametas [...]. Os indivíduos descendentes saem idênticos cromossomicamente ao organismo matriz [...] sexuada: implica a combinação de material genético (normalmente o DNA) de dois seres distintos (os progenitores) através da conjugação de duas células haploides (os gametas) por cariogamia [...] produzindo descendência variada.

Os alunos geralmente não se lembram do conceito de células somáticas devido a falta de pré-requisitos associada a complexidade dos conteúdos nessa área conceitual (TEKAIA, OKZUM \& SUNGUR, 2001), mas afirmam que as células crescem e o organismo também, sendo a mitose processo. Embora não completamente claro seja o pensamento conceitual desses alunos para um evento biológico, observamos indícios da elaboração do conceito em rede por eles: crescimento, célula, mitose e organismo. Neste sentido, a unidade funcional da célula/organismo pluricelular é um aspecto conceitual que merece atenção, pois articula interação sistêmica, tendo como base o conhecimento da estrutura e função celular e sua implicação correlata em nível de organismos, como o corpo humano, por exemplo, sendo este um conceito central e o primeiro, derivado (ZAMORA \& GUERRA, 1993; CASTRO, 2014).

Há um equilíbrio entre os conceitos funcionais científicos (4 F.C) e funcionais espontâneos (4 F.E) nos alunos que fizeram parte desta etapa da pesquisa, no que tange ao item 9 "se você tem diferentes células como estas, trabalham juntas como unidade?" Porém, faz necessário assinalar que para o primeiro, algumas respostas se aproximam da funcionalidade espontânea, como exposto a seguir: A1- "elas têm um mecanismo de funcionamento, onde cada uma tem sua função, uma depende da outra"; A8- "as células que são iguais se juntas e se formam os tecidos com eles formados começam a trabalhar". Contudo, as afirmações para o segundo não se aproximam do primeiro, evidenciando níveis de desenvolvimento conceitual distintos, em que os alunos estão iniciando o domínio dos conteúdos para a categoria F.C, em relação ao assunto mencionado, mas que mantêm características de F.E (conceito espontâneo). Assim, podemos assegurar que o conceito espontâneo funcional pode ser usado como base para edificação do conceito científico. O trecho exposto abaixo evidencia as afirmações supramencionadas: 
F.E- A2- Porque vai depender das funções de cada uma para o desenvolvimento do organismo. A3- Ao repassar informações as células, embora exerçam funções distintas, elas trabalham em conjuntos a fim de manterem o bom funcionamento da célula [...] ao passarem informação uma para a outra detectam o que o organismo necessita e assim enviam o que o organismo necessita. A4- Umas precisam das outras para um funcionamento, as células que compõem o intestino precisam que as células do estomago funcione bem também, é como se fossem uma corrente; de acordo com o papel que ela tem de desempenhar. Individualmente ou em grupo.

FC- A6- Através de processos homeostáticos que compreendem todos os órgãos tecidos e sistemas para o correto funcionamento do organismo. A7Elas trabalham em conjunto com outras células de características morfofisiológicas semelhantes [...] as células nervosas (neurônios, glias etc.) trabalham juntas; as digestivas de diferentes órgãos ou anexos da digestão; os músculos têm células fibrosas e resistentes. A8- As células que são iguais se juntas e se formam os tecidos com eles formados começam a trabalhar.

O conceito de unidade celular/organismo é explicado por um dos alunos da seguinte forma: "há um órgão ligando com filamentos o organismo, pelo sangue com ferro, as gorduras não são iguais para se nutrir" [...]. A afirmação do aluno parece indicar que existe, além do sangue, algum tipo de tecido que interconectam os órgãos e que se o organismo é nutrido por gorduras diferentes, é porque é devido funcionar de forma integrada. Percebemos que essa forma de compreensão se assemelha com um pensamento por complexo porque o aluno não consegue emitir explicação satisfatória cientificamente para os fatos, ou seja, articular as ideias de forma concisa. Assim, o surge a aparência de um pensamento conceitual, mas ainda limitada à abstração e percepção dos fenômenos/objetos em sua superfície (CASTRO, 2014).

Yorek, Sahin e Ugulu (2010) e Castro (2014) afirmam que a dificuldade de conceitualização dos alunos sobre célula como unidade básica de um ser vivo, como apresentada anteriormente, pode ser superada mediante um ensino voltado para funcionalidade da célula/organismo, desde o início da formação básica. Entretanto, se não é oportunizado tal ensino ao aluno durante o Ensino Fundamental e Médio, é salutar que na universidade seja disponibilizado aos estudantes um trabalho educativo voltado para tal necessidade. Isto pode favorecer a formação do conceito em rede mediante derivação conceitual, tendo como base um ensino em que o conceito funcional científico seja utilizado para edificar o conceito funcional espontâneo, tanto para o nível estrutural científico quanto para o funcional.

Evidenciamos que os conceitos de diferenciação celular e unidade do organismo/célula estão interconectados dentro de um sistema funcional. $\mathrm{O}$ aluno A7 afirma ainda que aos órgãos são constituídos por células diferentes devido à especialização das suas funções, a exemplo do cérebro (neurônios), intestino e pele, citando respectivamente suas funções como transmissão da informação genética, proteção, trocas de calor, absorção e digestão a partir das vilosidades. Este aluno associa ligeiramente a estrutura das células às funções desempenhadas por elas em seus tecidos. Ele afirma que células diferentes trabalham como unidade porque desenvolvem essas funções num mesmo órgão, exemplificando que no estômago há células epiteliais, nervosas, musculares etc. O aluno A4 acrescenta que a unidade celular/organismo é como uma corrente, envolvendo sangue, sistema nervoso, excretor, glândulas, mas num nível geral... Estes alunos têm um conhecimento morfofuncional básico e sistêmico acerca da 
célula/organismo, mas carecendo de algumas definições tanto morfo, quanto funcionais.

Os conceitos de hábito de vida e funcionamento celular/organismo cujo aspecto social se remete a uma explicação científica sólida foi pouco explicitado pelos estudantes de engenharia de pesca (3 semestre). Para o quesito "qual a relação do seu hábito de vida diário com o funcionamento celular? E com seu organismo? Houve 6 respostas funcionais espontâneas (F.E) e 2 funcionais científicas (2 F.C). Com base em Vygotsky (1991, 2010), o conceito vivenciado no dia a dia só pode ser explicado ou dominado pelo aluno quando o seu correspondente tiver sido plenamente desenvolvido na escola/universidade. Como acreditamos que existem dificuldades no ensino e/ou aprendizagem destes alunos, no que concerne aos conceitos de função celular/organismo, na formação básica e nos primeiros semestres do curso de engenharia de pesca, podemos compreender as diferenças conceituais apresentadas. Para este item, como exemplo de pensamento funcional espontâneo e funcional científico, temos, respectivamente:

\footnotetext{
F.E- A1- Quando se tem uma alimentação regulada, hábito de fazer exercício físico promove uma boa atividade e funcionamento da célula. A2- No desenvolvimento do meu organismo. A3- Cada célula responde de forma diferente de acordo com o modo de vida de cada individuo, bem como a adaptação do organismo. A5- Porque existem hábitos inadequados como falta de alimentação balanceada, falta de exercícios físicos, não dorme a quantidade de horas adequadas, que dificultam o bom funcionamento celular e assim compromete todas as funções do organismo. A7- Na parte funcional do corpo da alimentação, crescimento, saúde e sobrevivência. A8- No meu hábito de vida diário tenho uma boa alimentação um bom hábito. Com uma boa alimentação, as minhas células têm tudo o que precisa, sendo assim tendo um bom funcionamento o mesmo com o meu organismo.
}

FC- A4- Estamos em constante movimentação, consumimos e gastamos energia, com a célula é o mesmo, elas não para também consomem e liberam energia. A6- A depender de meus hábitos, nutrição e exigências minhas células terão demandas e funcionamento diferentes.

Um aluno acrescenta que "a uma pessoa pode ser saudável com exercício físico, ficando a célula e organismo de acordo com a atividade, sendo menor o hábito saudável, menor será funcionamento do organismo célula, sendo maior o hábito saudável, melhor a função do organismo célula". Para eles, desse modo, pode ser selecionado melhor o alimento/nutriente a ser absorvido pelo organismo.

O ensino dentro de um sistema conceitual na universidade pode ser direcionado do conceito geral (central) para o especifico (derivado) e vice-versa, tendo em vista que nem sempre é possível direcioná-lo por meio conceito central, mas buscando referência nele em seus aspectos estruturais e funcionais. Estes precisam estar ancorados no dia a dia mediante derivação conceitual, ou seja, podemos proporcionar explicações aos alunos acerca dos conceitos de ser vivo (central) que contribua para a compreensão do conceito de célula (derivado), sendo este também usado para auxiliar no domínio conceitual deles sobre ser vivo.

Inferimos que o ensino precisa prezar pela construção de conhecimento por meio de princípios científicos e não pela memorização de palavras que não explicam seu significado. Mas para ampliar o significado do conhecimento e/ou questões que os alunos trazem para escola/universidade, é preciso conhecer antes 
os conhecimentos prévios dos alunos e seus limites, suas formas/processos (frases e desenhos) relacionados aos aprendizados dos conteúdos após o ensino ministrado no ciclo básico da universidade (primeiros semestres).

\section{CONSIDERAÇÕES FINAIS}

Evidenciamos nesse trabalho que para os conceitos funcionais e estruturais específicos, os alunos do 3 o semestre do curso de engenharia de pesca da UNEB têm, no geral, um limitado conhecimento biológico. Para as 3 primeiras questões, sendo elas estruturais, a função das organelas, dos componentes celulares como membrana núcleo e componentes químicos/nutrientes não foi apresentada, no sentido de contribuir para ampliação do domínio do conceito de célula/ser vivo. Para as demais questões, envolvendo termos funcionais, houve explicação dividida pelos alunos para os conceitos espontâneos e científicos, tendo uma tendência maior para os primeiros.

Isto denota um débito no conhecimento científico por parte dos estudantes de engenharia de pesca acerca dos conteúdos ser vivo/célula. Contudo, consideramos que o grande número de conceitos funcional espontâneo apresentado por eles nessa área conceitual pode ser um forte ponto de partida para o ensino do conceito científico. Assim, as falhas na formação conceitual destes alunos na educação básica poderão ser supridas na graduação por meio de aulas ministradas em disciplinas afins, se o ensino tomar como base a visão atual deles sobre o assunto.

Em termos específicos, concebemos que um ensino direcionado a partir da funcionalidade espontânea dos estudantes poderá contribuir para compreensão de conceitos estruturais que dependem da definição conceitual, a exemplo do conteúdo composição da célula (nutrientes e organelas) que, na sua relação sistêmica, envolve seus aspectos químico, físicos e biológicos, integrando a célula ao organismo multicelulado (ex: corpo humano). Entretanto, este é um aspecto biológico pouco valorizado na pesquisa em educação, especialmente, quando se trata dos desenhos elaborados pelos adolescentes. Por isso, acreditamos ser indispensável identificar e conhecer os conceitos assimilados pelos alunos sobre estruturas biológicas celulares e do ser vivo, com vistas a contribuir com a análise das dificuldades de compreensão conceitual e dos possíveis avanços nos conhecimentos deles no referido curso. 


\title{
The conceptions about Living/Cell student third semester of fishing Engineering Campus XXIV-Xique-Xique, Bahia
}

\begin{abstract}
This work deals with the formation of scientific concepts in higher education of fishing engineering course at the State University of Bahia (UNEB), Campus XXIV-Xique-Xique, Bahia through knowledge gained by students in disciplines related to the biological sciences. Involved 8 students of 3rd semester basic cycle. Was based on the spontaneous and scientific conceptions of students about being alive/cell supported development phases studied by Vygotsky (abstract thought). We aimed to analyze the students ' knowledge about cell, cell differentiation, growth, respiration, reproduction, nutrition, heritage and unity. We use qualitative research linked the semi-structured interview. Data were analyzed according to the orientation of the dialectical method, and the responses of the students grouped in conceptual categories, compared and discussed according to the references presented. Showed the mechanisms involved in the assimilation of concepts spontaneous scientific and by students, highlighting their potentialities and difficulties of understanding.
\end{abstract}

KEYWORDS: Living. Cell. Scientific concept. 
1 Os estudantes em geral apresentaram um conhecimento científico limitado, tanto em relação aos conceitos biológicos centrais (ser vivo e crescimento), quanto para os derivados (tamanho de organismo/célula, diferenciação celular, composição química, transporte e absorção de nutrientes).

\section{REFERÊNCIAS}

BAHAR, M., JOHNSTONE, A., H., \& HANSELL, M., H. Revisiting Learning Difficulties in Biology. Journal of Biological Education 33: 84-87, 1999.

BAHIA. Secretaria de Educação. Orientações Curriculares Estaduais para o Ensino Médio: Área de Ciências da Natureza, Matemática e suas Tecnologias. SalvadorBA: Secretaria de Educação, 2005.

BOGDAN, R. C.; BIKLEN, S. K. A Investigação Qualitativa em Educação: uma introdução à teoria e aos métodos. Portugal: Porto Editora, 1994.

CABALLER, M. J.; GIMÉNEZ, I. Las ideas del alumnado sobre el concepto de célula al finalizar la educación general básica. Enseñanza de las Ciências, Barcelona, v. 11, n. 1, p. 63-68, 1993.

CASTRO, D.R. Estudo de Conceitos de Estrutura e Funcionalidade de Seres Vivos no Ensino Fundamental I. 2014. Tese (doutorado)- Universidade Federal da Bahia. Salvador, 2014.

CASTRO, D.R. Estudo de Conceitos de Seres Vivos nas Séries Iniciais. 2010. Dissertação (mestrado)- Universidade Federal da Bahia. Salvador, 2010.

GASPARIN, J. L. A construção dos conceitos científicos em sala de aula. Disponível em www.pesquisa.uncnet.br/.../ Acesso em 21/03/2007.

HOESE, WIlliam, J.; CASEN, Merry Lynn. Drawing out Misconceptions: Assessing stendent mental models in biology. Fullerton, March, 2007. Acesso em 16/09/2013. Disponível em http://bioliteracy.colorado.edu/Readings/papersSubmittedPDF/Hoese\%20and\%2 OCasem.pdf ZA Educational Strategies in Science and Mathematics, Misconceptions Trust: Ithaca, NY (1993). 
MILES, M. B.; HUBERMAN, A. M. Qualitative Data Analysis. 2nd ed. London: SAGE Publications, 1994.

MOURA, M. P., (2000). Desenvolvimento do pensamento: um estudo sobre formação de conceitos com jovens e adultos em processo de escolarização. São Paulo: Universidade de São Paulo (dissertação de mestrado apresentada).

MOHAPATRA, Animesh K. MOHAPATRA, Reena. Effect of animations in constructing and reconstructing students' knowledge of cell division (mitosis) Bhubaneswar, India. Proceedings of epiSTEME 4, 358-362pp. S/D. Acesso em 16/09/2013. Disponível em http://episteme4.hbcse.tifr.res.in/proceedings/strand-iii-curriculum-andpedagogical-studies-in-stme/mohapatra-mohapatra

SHAEFER, G. Concept Formation in Biology: The Concept 'Growth'. European Journal of Science Education. Vol. 1, Issue 1, 1979.

TEIXEIRA, F. M. Teorias sobre a origem do conhecimento biológico na infância: avanços, limites e implicações. Educ. Rev. [online], n.39, pp. 61-78, 2004. ISSN 0102-4698.

TEKKA YA, C.; ÖZKAN, Ö.; SUNGUR, S. Biology Concepts Perceived as Difficult by Turkish High School Students. Hacettepe Üniversitesi Eğitim Fakültesi Dergisi 21: 145-150 \{200I]

TRIVIÑOS, A. N. S. Introdução à pesquisa em ciências sociais: a pesquisa qualitativa em educação. São Paulo: Atlas, 1987.

VYGOTSKY, L. S. Pensamento e linguagem. São Paulo: Martins Fontes, 1991.

A Construção do Pensamento e da Linguagem. 2. ed. São Paulo: Martins Fontes, 2010.

YOREK, N.; SAHIN, M.; UGULU, I. Students' representations of the cell concept from 6 to11 grades: Persistence of the "fried-egg model". International Journal of Physical Sciences, v. 5 (01), p. 15-24, jan. 2010. Available online at <http://www.academicjournals.org/IJPS>. Acesso em: 20 mar. 2013.

YOREK, N.; SAHIN, M.; AYDIN, H. Are Animals 'More Alive' than Plants. AnimistAnthropocentric Construction of Life Concept. EURASIA, J. Math. Sci. Technol. Educ. 5 (4) 369-378, 2009. 
ZAMORA, M.C.; SILVIA, E.; GUERRA, María. Misconceptions about cells: in The Proceedings of the Third International Seminar on Misconceptions and Educational Strategies in Science and Mathematics, Misconceptions Trust: Ithaca, 2NY (1993).

Recebido: 09 jan. 2015.

Aprovado: 07 mar. 2016.

DOI: $10.3895 /$ rbect.v9n1.2090

Como citar:

CASTRO, D. R. et al. As concepções sobre Ser Vivo/Célula dos Estudantes do 30 semestre do Curso de Engenharia de Pesca do Campus XXIV- Xique-Xique-BA. Revista Brasileira de Ensino de Ciência e Tecnologia, v. 9, n. 1, p. 301-325, jan./abr. 2016. Disponível em:

<https://periodicos.utfpr.edu.br/rbect/article/view/2090>. Acesso em: xxx. Correspondência:

Darcy Ribeiro de Castro

Rua João Guimarães, 1032, São Francisco, 47.400-000 Jacqueline de Araújo Guerra

Rua João Guimarães, 1032, São Francisco, 47.400-000

Keisyara Bonfim dos Santos

Rua João Guimarães, 1032, São Francisco, 47.400-000

Nadijara Pereira dos Santos

Rua João Guimarães, 1032, São Francisco, 47.400-000

Samara Rocha Mendes dos Santos

Rua João Guimarães, 1032, São Francisco, 47.400-000

Taliany Santos de Amorim

Rua João Guimarães, 1032, São Francisco, 47.400-000

Direito autoral: Este artigo está licenciado sob os termos da Licença Creative Commons-Atribuição 4.0 Internacional. 